\title{
Towards a holistic view of corporate social responsibility. The antecedent role of information asymmetry and cognitive distance
}

\author{
Francesco Caputo \\ Department of Economics, Management and Institutions, \\ University of Naples Federico II, Naples, Italy
}

Antecedent role of information asymmetry

Received 30 January 2020 Revised 20 April 2020 27 June 2020 5 August 2020 Accepted 17 August 2020

\begin{abstract}
Purpose - This paper aims to enlarge ongoing debate about corporate social responsibility (CSR) proposing reflections about the role of cognitive and information flows in influencing companies' approaches and market expectations related to CSR.

Design/methodology/approach - The paper builds upon the research streams related to the information asymmetry and cognitive distance, for identifying through the interpretative lens provided by systems studies, possible key drivers on which policymakers, researchers and practitioners should act for building a suitable, shared and long-term oriented path for CSR.

Findings - The paper defines a scenario map about CSR in the light of information asymmetry and cognitive distance. Such a map supports both researchers and practitioners in better understanding actions and paths required for building a shared approach to CSR.

Research limitations/implications - Recognizing the multidimensionality of CSR and the multiple managerial and organizational contributions provided for underling its advantages for companies, the paper focuses the attention on the elements and conditions able to promote, stimulate and encourage companies' CSR strategies.

Originality/value - The paper provides a fresh conceptual framework for explaining conditions and elements required for ensuring the success of strategies for CSR. Adopting a systems view, the paper overcomes the limitations related to a reductionist view about advantages and results of CSR to call the attention on the conditions that should be met for ensuring the emergence of a shared approach to CSR.
\end{abstract}

Keywords Corporate social responsibility, Information asymmetry, Cognitive distance,

Antecedents, Systems studies

Paper type Conceptual paper

\section{Introduction}

The increasing turbulence of social and economic dynamics is underling the need for identifying new paths, models and instruments able to ensure companies' survival (Jensen, 2018). Consolidated managerial approaches and business models are showing an increasing uselessness in supporting both researchers and practitioners in understanding the multiple

(C) Francesco Caputo. Published by Emerald Publishing Limited. This article is published under the Creative Commons Attribution (CC BY 4.0) licence. Anyone may reproduce, distribute, translate and create derivative works of this article (for both commercial and non-commercial purposes), subject to full attribution to the original publication and authors. The full terms of this licence may be seen at http://creativecommons.org/licences/by/4.0/legalcode

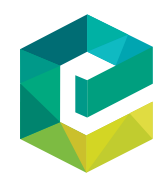

Kybernetes Vol. 50 No. 3,2021 pp. $639-655$ Emerald Publishing Limited $0368-492 \mathrm{X}$ 
$\mathrm{K}$

50,3

640

interrelated dimensions able to affect companies' performance (Foss and Saebi, 2018; Lepskiy, 2018). As a consequence, a multi-disciplinary effort is required for overcoming consolidated perspectives and for identifying new pillars on which to build innovative interpretative frameworks and managerial guidelines (Barile et al., 2014; Saviano et al., 2018).

In such a vein, in the past few decades, an increasing number of researchers and practitioners have shift the attention from the study of companies' internal dynamics to the analysis of companies' interactions with its environment (Arévalo and Espinosa, 2015; Tronvoll et al., 2018). The attention has been focused on several interesting domains such as the consumers' perspectives (Holbrook, 1999), the relationships inside socio-economic systems (Tomer, 2002; Caputo et al., 2019) and the conditions for power and influence within the market (Marin and Verdier, 2008).

As a consequence of the shift from a company-centred perspective to an environment-based perspective, new challenging reflections have been developed under the conceptual umbrella of sustainability as science interested in identifying conditions and processes for ensuring the balance among society, economy and environment domains (Espinosa and Walker, 2017; Barile and Saviano, 2018). Specifically, multiple discussions have addressed the role of companies in the network of relationships within socio-economic contexts (Espinosa et al., 2007; Hollensen, 2010), the need to focus the attention on companies' impact on society and environment balances (Knowles and Espinosa, 2009; Baumgartner and Ebner, 2010) and on the effects that companies' attention to sustainability pillars can have on market behaviours (Del Giudice et al., 2017).

With specific reference to this latter point, several researchers have tried to demonstrate that companies' attention to corporate responsibility influences companies' performances (Burhan and Rahmanti, 2012) also as a consequence of its influence on market perceptions (Laszlo, 2003). Coherently, it has underlined the need for companies to efficiently communicate their attention to corporate responsibility underling their effort in respecting social, economic and environmental principles in the light of a wider perspective of sustainable development for all (Caputo et al., 2018). In such a scenario, corporate social responsibility (CSR) as "the continuing commitment by business to behave ethically and contribute to economic development while improving the quality of life of the work-force and their families as well as of the local community and society at large" (World Business Council for Sustainable Development [WBCSD], 1999, p. 3) has become a central concept of contemporary business and economic literature.

To tell the truth, Porter and Kramer (2006: p. 2) highlight that:

[...] heightened corporate attention to CSR has not been entirely voluntary. Many companies awoke to it only after being surprised by public responses to issues they had not previously thought were part of their business responsibilities.

This idea comes from a weak approach to sustainability within which businesses are more interested in gaining reputation (think for example, to the greenwashing) than in adopting a stronger and more responsible approach to sustainability (Bowen, 2014; Panagiotakopoulos et al., 2016).

Unfortunately, the multidimensionality of CSR usually is underestimated in social and managerial studies and the large part of existing contributions focuses the attention only on the effects of CSR on companies' performances, market orientation and consumers behaviours.

With the aim to bridge this gap in knowledge, the paper recognizes that any systemic study to CSR requires to overcome the consolidated reductionist approach for depicting the multi-dimensionality and the multiple connections through which organizational systems interact for defining their idea, behaviours and decisions (Docherty et al., 2008; Espinosa et al., 2008; Espejo and Espinosa, 2015). In such a vein, useful key lines have been traced by Mulej's dialectical systems theory (DST) (Mulej, 1976) for which: 
- Any human decision, action and behaviour depend on a subjective perception related to a set of conditions based on the individual cognitive balance and orientation.

- The perception influences human understanding and evaluation about events and processes.

Antecedent role of information asymmetry

- Actors' "attempts" to be holistic are affected by a partial and subjective representation of reality then a common holistic representation of reality is not possible.

DST is used as a fundamental base on which reflections herein are developed because it represents one of the preliminary applications of systems theory in social sciences. As underlined by Zenko et al. (2012), DST tries to overcome reductionism recognizing that a holistic view is required for effectively understanding in which ways systems interact creating conditions for reciprocal influence.

In the past century, several systems-based research streams (Beer, 1989; Espejo, 1990; Checkland, 1994; Schwaninger, 2006; Barile et al., 2018) have tried to build a conceptual framework able to combine multiple perspectives in a whole representation and more concepts have been used such as ecosystem (Tansley, 1939), complex systems (Ashby, 1991) and complex adaptive systems (Holland, 1992).

Building upon the challenging and multidisciplinary interpretative frameworks proposed by all these contributors among others and using the interpretative lens provided by DST, the paper aims at extending the ongoing debate about the CSR in the domain of social and economic studies. In such a vein, some reflections about the antecedents in the path forward CSR are proposed focusing the attention on the domains of information asymmetry and cognitive distance.

Following this line, the rest of the paper is structured as follows: in Section 2, the theoretical background is described, and a brief presentation of CSR, information asymmetry and cognitive distance is proposed. In Section 3, a framework for organizing consolidated approaches to CSR is proposed. In Section 4, an overview of main concepts herein and their implications and limitations are discussed. Finally, in Section 5, preliminary final remarks are proposed and possible future directions for research are traced.

\section{Theoretical background}

\subsection{Overview of corporate social responsibility evolution and its systems implications}

The concept of CSR is not new in managerial and social studies. Preliminary contributions have been proposed in the first decades of 19th century (Barnard, 1938) but only during the 1950s the studies about CSR have attracted an increasing attention and a multidimensional research stream has been defined (Deigh et al., 2016).

Over the time, the concept of CSR has been investigated from several perspectives (McWilliams and Siegel, 2001; Mosca and Civera, 2017). One of the most shine reviews of the evolutionary process that have affected the "history of CSR" has been provided by Carroll (1999), for which five-time based phases can be identified:

(1) The modern era of social responsibility begins: the 1950s. In this phase, the attention is strongly focused on the social responsibility and preliminary contributions about the domain of CSR are provided by Howard Bowen with the book "Social Responsibilities of the Businessman" (1953) in which a call is 
$\mathrm{K}$

50,3

\section{2}

formulated for attracting the attention of decision-makers, policymakers, researchers and practitioners about the "responsibilities of business" with reference to environment protection.

(2) CSR literature expands: the 1960s. In this phase, the concept of CSR is enforced through the elaboration of preliminary definitions. The attention is on businessmen's behaviours and on their influences on society and environment balances (Davis, 1960).

(3) Definitions of CSR proliferate: the 1970s. In the 1970s, the concept of CSR reaches its maturity and constructive reviews of previous contributions are proposed for systemizing the state of knowledge. In this phase, the CSR presented is not as simple as the results of companies' commitment for respecting society and environment balances but - in a more widen perspective - it is related to the "multiplicity of interests" that stakeholders can show in companies' actions and decisions and then companies must respect if they want to survive over the time.

(4) The 1980s: fewer definitions, more research and alternative theme. During the 1980s, the multidimensionality of CSR is fully recognized by researchers and practitioners and several research streams emerge for investigating the multiple dimensions of CSR. In this phase, CSR becomes a conceptual umbrella able to embrace the multiple processes, activities and strategies than influence actors' behaviours as a consequence of their perceptions about companies' responsibility, ethics and correctness.

(5) The 1990s: CSR further yields to alternative themes. In this phase, CSR is definitively recognized as element of corporate strategies and multiple models are proposed for underling the contribution of CSR to companies' performance and for supporting researchers and practitioners in better managing the levers of CSR.

In addition to the five-time based phases identified by Carroll (1999), the following two phases can be considered:

(1) The 2000s: the emerging market of CSR. In this phase, a pervasive interest on CSR emerges and stakeholders show an increasing attention towards companies' ability to efficiently communicate their attention to social responsibility and environment balance. Accordingly, CSR shows all its relevance as possible lever for influencing stakeholders' perceptions about companies positioning.

(2) The 2010s: the era of regulation. In this phase, policymakers show an increasing attention on the domain of CSR and multiple guidelines and rules are promoted and approved for addressing companies' behaviours. Among the others, the UNI ISO 26000:2010 for social responsibility is approved for supporting companies in promoting the sustainable development and the Occupational Health and Safety Assessment Series standard is revised for ensuring the emergence of an integrated system for quality, safety and environment management.

The summary proposed by Carroll (1999) offers the opportunity for understanding in which ways the concept of CSR has changed over the time as a consequence of the different perspectives adopted for investigating its dimensions and implications. Specifically, it is possible to note how the interpretative frameworks adopted in the studies of CSR have shifted from a more general view based on the combinations of environment, social and economic dimensions (1960s and 1970s) to a more specialistic and performance-oriented view principally interested in companies' behaviours and actions (1980s and 1990s). 
Reflecting upon the challenging dynamics of CSR domain over the time, it is possible to underline the need for defining new potential interpretative paths able to approach CSR as a construct that:

[...] requires humans to think, decide, and act on a very broad basis rather than to focus only on profits [this is required because] profit defined too narrowly as the main motivation destroys profit as an outcome by causing too many problems and costs, which can be avoided by CSR (Knez-Riedl et al., 2006, p. 442).

Antecedent role of information asymmetry

In such a direction, few basic laws can be derived from Mulej's (1976) DST to trace the path for a shared CSR less influenced by economic dimension and able to consider the coexistence among economy, environment and society (Knez-Riedl et al., 2006):

- The law of entropy, according to which everything changes over the time for defining new balances, rules and trends.

- The law of requisite holism related to the impossibility for defining a complete picture of social, environmental and economy dynamics as a basic assumption according to which each decision is affected by the individual ability to catch, understand and explain internal and external dynamics.

- The law of hierarchy of succession and interdependence for which processes and actions cannot be analysed focusing the attention on the relationships among the parts with the aim to define a possible hierarchy. Processes and actions emerge as the result of a constant interconnection, interdependence and exchange among the multiple systems involved in the same context.

Reflecting upon the three abovementioned laws, it is possible to underline and (perhaps) to explain how changes in social and economic configurations have disrupted previous balances requiring new managerial models and business approaches. This emerging need can also be perceived with reference to the domain of CSR for which a step back is required to understand not only its implications and effects but also its causes and antecedents. With this aim, in the next subsection, the concepts of information asymmetry and cognitive distance are briefly presented for clarifying their role as antecedents of CSR and for underling possible gaps in knowledge in consolidated contributions about CSR. Basically, information asymmetry and cognitive distance are approached as antecedents of CSR because they are domains able to explain actors' approach to CSR as a consequence of their perceptions about the conditions related to Mulej's (1976) laws. According to the adopted interpretative view, entropy, requisite holism and hierarchy of succession and interdependence can have different meanings and they can be differently perceived and understood by each actor as a consequence of the total amount of information owned with reference to the topic under analysis (information asymmetry) and in relation to the subjective relevance of the topic under analysis (cognitive distance).

\subsection{Role of information and cognition for building a shared system}

As underlined by Uhl-Bien et al. (2007), we are living in the knowledge era. An era in which information is becoming the new source of power for social and economic actors (Caputo, 2017). The abilities for accessing information, for organising them in structured models and for using them as a source of competitive advantage are progressively becoming central in managerial and organizational literature (Bashir and Farooq, 2019).

Focusing the attention on the conditions than can (positively or negatively) influence information flows, interesting stimuli for reflections can be derived from the research 
$\mathrm{K}$

50,3

644

streams rooted in the concepts of information asymmetry (Akerlof, 1978) and cognitive distance (Nooteboom et al., 2007).

Explicitly, information asymmetry recurs every time the actors involved in a relationship have different amounts of information about exchanged goods or provided services (Caputo and Evangelista, 2019). As a consequence of this difference in information equipment, actors with more information could adopt speculative behaviours to increase their market power (Krishnaswami and Subramaniam, 1999; Perko and Mlinaric, 2016). More specifically, information asymmetry can influence relationships at two different levels (Mulej et al., 2006):

- Preventive or ex-ante information asymmetry, in the case in which one party hides information that has a relevant role in defining conditions and results of the transaction. This condition is also known as adverse selection.

- Successive or ex-post information asymmetry, in the case in which one party does not respect conditions of transactions for obtaining a personal advantage and/or benefit. This condition is also known as moral hazard.

From the other side, cognitive distance refers to the difference among individuals' social, cultural and general life experiences (Harrison-Hill, 2001; Breidbach and Brodie, 2017). This difference pushes the involved actors towards different aims through pathways and behaviours that could not be complementary with multiple negative effects on the possibility for the relationship to produce value (Singh and Giacosa, 2019). Using Zack's (2003) classification for analysing knowledge-based organizations, it is possible to state that cognitive distance acts on:

- Process as a set of actions through which existing knowledge is used and/or new knowledge is created. In such a dimension, cognitive distance reduces the possibility for combining internal knowledge asset with several negative consequences in terms of knowledge creating and sharing learning.

- Place as set of elements through which actors interact for defining a shared and safe environment. Conditions of cognitive distance influence involved actors in defining different perspectives about the shared environment reducing the opportunities for an effective knowledge sharing.

- Purpose as complex of finalities achieved by all the actors involved in a specific process and/or structure. With reference to this element, cognitive distance influences involved actors in the definition of priorities among the multiple pursued aims provoking misaligned behaviours and actions able to affect system's balance and survival.

- Perspective related to the subjective views on which they are based i.e. expectations, aims and willingness of involved actors. Conditions of cognitive distance can produce speculative behaviours addressed to ensure individual satisfaction at the expense of the whole system.

Recognizing the key role of information asymmetry and cognitive distance in ensuring the emergence of conditions for building a shared system, it is possible to state that while information asymmetry influences the relationship contributing to the definition of power conditions, cognitive distance acts at the beginning of the relationship influencing the willingness and orientation of actors in sharing information. The pillars of information asymmetry and cognitive distance offer the opportunity for understanding conditions and antecedents in the process for acquiring and sharing information. 
As a matter of fact, actors are interested in acquiring information about companies and organizations for avoiding conditions of information asymmetry and for defending their market power while cognitive distance influences actors' level of attention towards companies' communications and it conditions actors' ability for understanding companies' communication and actors' willingness to believe in companies' communication.

According to this, few basic conditions should recur for avoiding the emergence of information asymmetry and/or cognitive distance in any strategies direct to build a transparent, shared and long-term oriented relationship among multiple actors (Mulej et al.,

Antecedent role of information asymmetry

645 2006, p. 1,011):

- participants must be interdependent and must be aware of it;

- participants must possess a minimum of the required public information;

- participants must possess their own private information which matter for their cooperation;

- private information must be available for sharing with other participant;

- participants must know how to organize their sharing and cooperation; and

- participants must have an organizational possibility to cooperate.

\section{Towards a holistic view of corporate social responsibility}

As underlined in Section 2.1, CSR is a multidimensional concept focused on companies' activities, processes and actions directed to underline companies' willingness and engagement in respecting the multiple dimensions that influence social, economic and environmental balances (Soltani and Navimipour, 2016). CSR goes beyond laws and national rules and it refers to the voluntary engagement of companies in promoting paths and actions able to ensure a sustainable development for all the actors (Ritter and Geersbro, 2018).

As a consequence of its finalities, CSR has a great power in influencing market perceptions about companies' behaviours and strategies and - for this reason - it is also used as a marketing instrument for conditioning consumers' willingness to interact with companies (Podnar and Golob, 2007). In such a vein, it emerges the need for better understanding elements and conditions able to influence the effectiveness of CSR approaches as companies' instrument for valorising their social engagement (Caputo and Evangelista, 2019).

In such a direction, DST's ten guidelines can be followed as traced by Čančer and Mulej (2010, p. 291) for building a possible interpretative model:

- purpose to create something new against entropy;

- approach to reach the purpose in a new way;

- what, precisely, are the trouble, the objective and the tasks, as a system rather than a set;

- how, precisely, does the procedure go with each task;

- covering everything important;

- requisite holism on the basis of capability of creative co-operation (by dialectical thinking);

- dialogue and organized co-operation making holism possible;

- continuous updating;

- interdependence of knowledge and emotions; and

- evolution and intuition. 
$\mathrm{K}$

50,3

646

Following DST's guidelines, it is possible to recognize that approaches and models for CSR cannot be developed without considering elements and conditions able to influence the interests towards CSR both in companies' and stakeholders' perspectives. In such a direction, information asymmetry and cognitive distance are approached as domains able to influence both companies' and stakeholders' perspective about CSR and four alternatives scenario are speculated as summarized in the following Figure 1.

As shown in Figure 1, focusing the attention on information asymmetry and cognitive distance as possible domains able to explain the antecedents in the path towards CSR both in companies' and stakeholders' perspectives, it is possible to identify four CSR scenarios:

(1) Defence scenario in which stakeholders' attention in CSR practices is motivated by the willingness to avoid companies' not socially responsible behaviours in terms of greenwashing or not true sustainability-based declaration. In such a scenario, stakeholders are interested in acquiring information about companies' strategies and behaviours for evaluating their impacts on society and environment balances. Stakeholder tends to acquire more information about companies' practices with the aim to evaluate the multiple dimensions behind companies' strategies. A clear example of this configuration is related to the increasing attention to corporate social reports (Calabrese and Lancioni, 2008) and to the "explicative" role given to the product labels (Carrero and Valor, 2012) as instruments through which stakeholder tries to collect direct information about companies' actions.

(2) Influence scenario in which companies are interested in promoting CSR approaches as a way for influencing stakeholders' perceptions and stakeholders' evaluations about companies' behaviours and strategies. In such a scenario, CSR is used by the company as an instrument for providing planned information through which the company can affect stakeholders' knowledge perception. Accordingly, CSR is a way for increasing information asymmetry as a way through which companies can better influence market behaviours. This scenario includes and describes basic assumptions on which marketing strategies routed around sustainability, green and environment are defined (Papadas et al., 2017). As well summarized by Jahdi and Acikdilli (2009, p. 106), companies involved must communicate with stakeholders "not only to convince them that the company is serious about its CSR

Figure 1.

A matrix for CSR scenarios in the light information asymmetry and cognitive distance

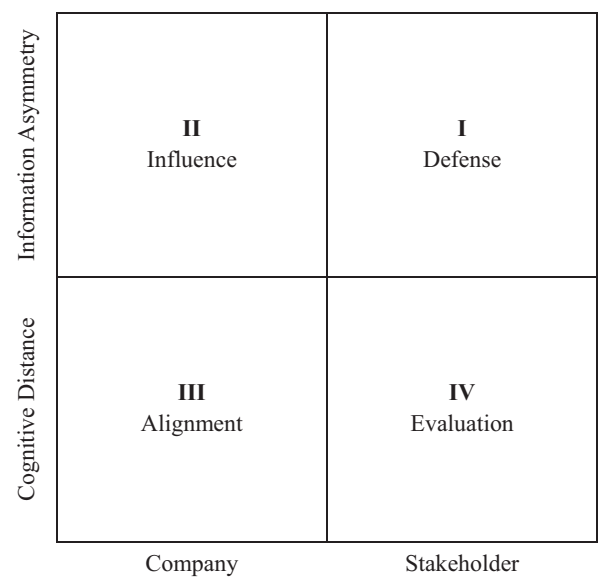


strategies, but also to reap benefits that come with such an image, e.g. competitive edge, keeping out new entrants, avoiding penalties for unethical behaviour, preempting the impact of future legislation as well as long-term investment in corporate image".

(3) Alignment scenario in which companies use CSR as a way for increasing their alignment with stakeholders' strong beliefs and perspectives. In such a scenario, CSR is usually used by companies as a way for attracting stakeholders with similar interests and perspectives. This configuration is related to the concept of knowledge alignment under which CSR is considered as a set of strong beliefs able to influence actors' behaviours towards common purposes. Key concepts behind this scenario are well summarized by Menichini and Rosati (2014, pp. 360-361) for which "feedback on CSR activities allows companies to understand consumer preferences about social and environmental problems and, consequently, help companies to align themselves with consumer values and beliefs".

(4) Evaluation scenario in which stakeholder are interested in CSR as a way for understanding if companies are influenced by strong beliefs, finalities and perspectives that can be considered aligned with their views. In such a scenario, CSR supports stakeholders in verifying if there are conditions of compatibility with the company. This scenario recognizes the existence of multiple factors able to influence stakeholder willingness and behaviours within the market. Overcoming a rational and transactional view of socio-economic relationships, this scenario includes and summarizes all contributions related to cognitive dimensions and involvement within CSR framework (Pirsch et al., 2007; Chaudhary, 2017). In this configuration are included the two sub-dimensions of CSR identified by Richter and Arndt (2018, p. 589): Identity orientation that "refers to the commonly shared assumptions by stakeholders what the firm is, and is expected to affect motivation and behavior" and legitimacy that "describes the act of seeking legitimacy among organizational stakeholders for what a firm does, how it does it and the way things are done".

The simple matrix proposed in Figure 1 offers an effective support to all researchers and practitioners interested in analysing state of art and dynamics of CSR strategies. Focusing the attention on the two main actors interested in a CSR strategy, Figure 1 provides useful information about the relationships among the actors involved and interested in CSR. At the same time, the map shown in Figure 1 can support decision-makers in defining an effective strategy for CSR supporting an evolution path along the four proposed configurations.

Basically, the matrix aims at enriching existing theoretical and practical knowledge about CSR providing insights with reference to:

(1) The management of alignment between companies and stakeholders with reference to the domain of CSR. With reference to this point, the matrix offers the opportunities for depicting three different strategies as summarized in the following Figure 2:

- With reference to the Defence scenario, company should provide more information about their interest in CRS. Thanks to this approach, companies have the opportunities for increasing the stakeholders' trust about effective engagement of companies in CSR practices. As a consequence, stakeholders will be more oriented in developing collaborative and long-term relationships with the company. 
$\mathrm{K}$
50,3

\section{8}

Figure 2.

Companies' strategies within CSR scenarios in the light of information asymmetry and cognitive distance

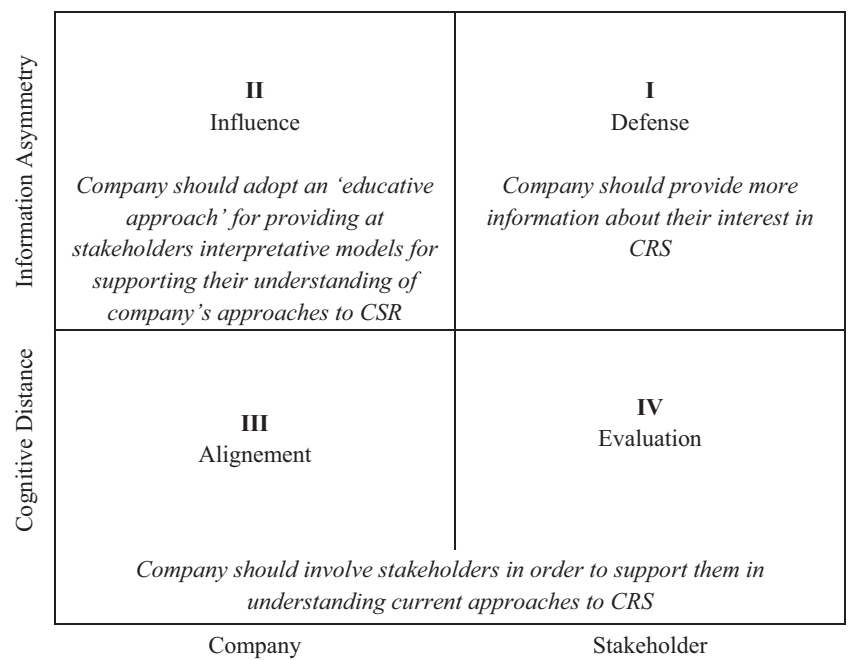

- With reference to the influence scenario, company should adopt an "educational approach" for providing stakeholders interpretative models for supporting their understanding of company's approaches to CSR. In the case in which company want to influence market's perception, it should invest in communication strategies direct to support the definition of shared interpretative models through which stakeholders can effectively understand company's engagement in CSR field. Accordingly, company should emphasize dimensions of CSR (for example, gender equality, social inclusion and environmental protection) with reference to which it is more active with respect to the competitors.

- With reference to the alignment and evaluation scenarios, company should involve stakeholders to support them in understanding current approaches to CSR. This strategy is direct to support the definition of shared paths in which stakeholder are active parts. In such a direction, company can create virtual platforms through which to collect stakeholders' suggestions and comments, it can offer to the stakeholders the possibility for evaluating the products before they are available for the market and it can propose programs through which stakeholders have the opportunities to directly participate in the design process of new products suggesting on which elements to pay more attention for increasing products' alignment to sustainability science recommendations.

(2) A possible evolution path along which stakeholders-companies relationship can evolve within CSR domain. As show in the following Figure 3, it is possible to speculate that the prevalence of a companies' weak approach to sustainability and the increasing attention of companies towards the marketing advantages that it is possible to obtain from CSR approaches, pushes a large part of existing companies in the influence scenario in which more attention is paid with reference to the actions able to "manipulate" stakeholders' perception. As a consequence of this, stakeholders adopt a defence approach because they are not able to easily understand which companies are really interested in developing CSR strategies. In 


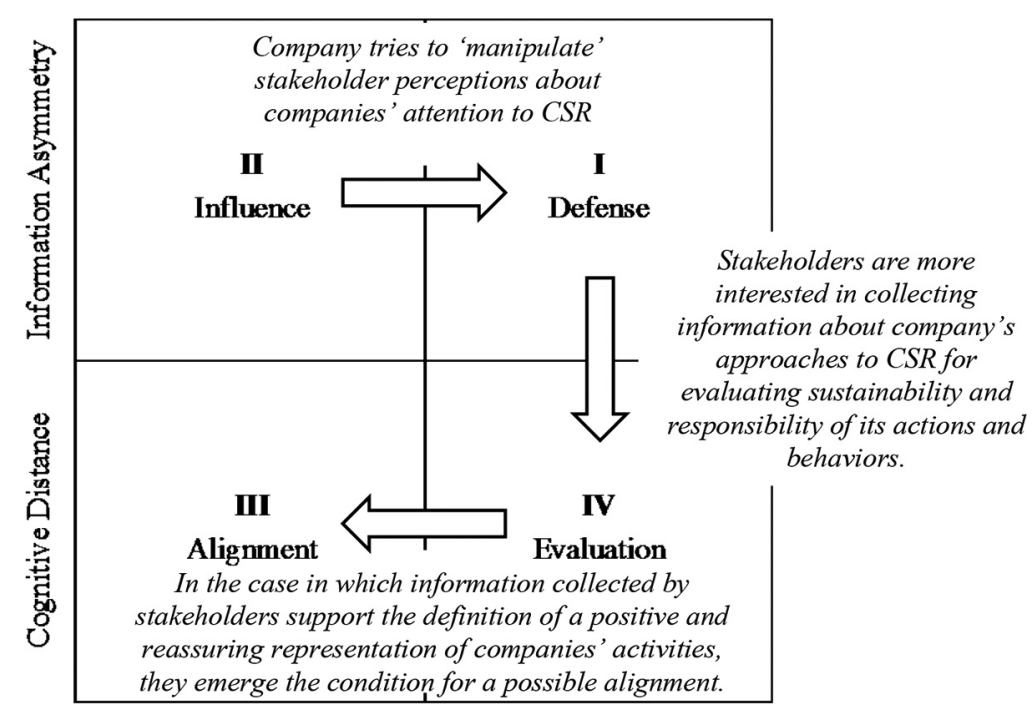

Company

Stakeholder
Antecedent role of information asymmetry

649

Figure 3. A path for stakeholderscompanies relationship within CSR domain

line with this, stakeholders try to collect more information about companies' strategies, and they are more interested in companies' voluntary disclosure as ways through which they can evaluate companies' approaches. Finally, if information collected by the stakeholders support the definition of a positive and reassuring representation of companies' activities, they emerge the condition for a possible alignment and for a collaborative and long-term relationship.

\section{Discussions, implications and limitations}

CSR can be considered as one of the most challenging topics addressed by social and managerial literature in the past few decades. The multiple perspectives that CSR should considered, the problems related to its definition and its implications on businessenvironment relationship have attracted the interests of multiple researchers and research streams (Luciano et al., 2013).

Tracing the main phases that have defined the evolution of CSR, it clearly emerges a progressive increasing attention on the elements able to justify companies' attention on social responsibility as a way for reducing existing distance to the market (Bertoncelj and Kovač, 2009). The prevalence of a companies' weak approach to CSR more interested in ensuring marketing advantages rather than to promote strategies interested in ensuring a balanced relation among environment, economy and society, have progressively compromised the real nature of CSR also reducing the disruptive role of the key concepts on which social responsibility should be based.

Basically, CSR should be direct to emphasize the need for defining models, instruments and approaches through which to support actors' alignment and reciprocal understanding to ensure mutual satisfaction and future opportunities for growth and development (Wu et al., 2012).

Building upon this basic assumption, the paper tries to extend existing social and managerial perspectives in the CSR domain using the interpretative lens provided by 
$\mathrm{K}$

50,3

650

Mulej's DST for recalling the attention on the need for a holistic approach to CSR. In such a vein, the key role of information asymmetry and cognitive distance has been investigated with the aim to support researchers in focusing the attention on the multiple ways through which they can influence emergence and success of a CSR strategy both from companies and stakeholders' side.

Thanks to the matrix provided in Figure 1, it is possible to emphasize the multi dimensionality of CSR and to underline in which ways actors' approaches to CSR are influenced by existing perceptions and by aims pursued by involving actors. Building upon the challenging domains of information asymmetry and cognitive distance, the matrix recalls the attention of the cognitive elements able to influence actors' willingness to build collaborative relationships able to support the emergence of a shared approach to CSR. At the same time, the matrix also provides interesting stimuli for reflections to all the practitioners interested in CSR through the definition of a potential evolution path through which to overcome a reductionist view of CSR and for embracing a wider assessment in which the attention is on the complex of cognitive elements able to influence companiesstakeholders relationships.

Anyway, the paper only provides a fresh conceptual framework for combining existing knowledge in an innovative way. All the theoretical reflections herein require to be verified combining qualitative and quantitative study able to provide evidence about the ways in which differences in perspectives, information and knowledge effectively influence actors' approach to CSR. Basic assumptions herein are inspired by the key pillars on which DST is based and their validity requires to be widely analysed in the light of the multiple systemsbased contributions and theories interested in overcoming boundaries and limitations of reductionist view in social sciences.

\section{Final remarks and future directions for research}

CSR is a multidimensional topic that is attracting the interest of both researchers and practitioners interested in managerial and organization fields. The state of literature shows that CSR is usually analysed with reference to its role in supporting companies for better communicating their engagement in social activities and their attention to environment balance.

Thanks to the interpretative contributions provided by the concepts of information asymmetry and cognitive distance, the paper shows that it is possible to identify multiple possible scenarios for CSR and then each of them emerge as a consequence of different needs of companies and stakeholders. The four identified scenarios (defence scenario, influence scenario, alignment scenario and evaluation scenario) show the complexity of CSR recalling the attention on the multiple ways through which interested actors can interact and they represent a call for developing multiple approaches and models for approaching, studying and managing CSR.

Each of the four abovementioned scenario represents a protentional building block for extending managerial and organizational contributions in the field of CSR through the development of models and approaches able to facilitate the match between companies and stakeholders. Accordingly, the four abovementioned scenarios represent a way through which to overcome "the traditional trend from most organisations to operate within hierarchical top-down approaches" (Knowles and Espinosa, 2009, p. 281) not able to ensure an effective and shared engagement for facing the challenge of sustainability. By focusing the attention on companies-stakeholders relationships, the paper tries to support the shift from a top-down to a bottom-up approach to sustainability as a way for stimulating strong approaches instead of weak approaches to sustainability. 
Basically, the paper enriches existing and consolidated knowledge about CSR providing a fresh conceptual framework in which the challenging domains of information asymmetry and cognitive distance contribute to depict the multiplicity of interests, aims and perceptions able to influence companies-stakeholders relationships with reference to CSR field. Unfortunately, the paper only focuses the attention on the conceptual foundations and on their development for building a possible conceptual model and more attention will be reserved to the validation and application of proposed model in the next research studies through the analysis of case studies able to provide evidences about the four speculated scenarios.

According to the reflections herein, CSR can be considered as one of the most challenging topics that will interest social and managerial studies in the next few years. In such a direction, it clearly emerges the need for defining strong pillars on which to build a holistic approach to the ways in which companies' and stakeholders' attention to social responsibility can influence their perspectives, decisions and actions. A systems view is then required for extending the view from the "simple" outcomes to the complex elements engaged in (Lepskiy, 1998; Perko and Ototsky, 2016; Saviano et al., 2017).

\section{References}

Akerlof, G.A. (1978), "The market for 'lemons': quality uncertainty and the market mechanism”, In Uncertainty in Economics, Academic Press, New York, NY, pp. 235-251.

Arévalo, L.E.B. and Espinosa, A. (2015), "Theoretical approaches to managing complexity in organizations: a comparative analysis", Estudios Gerenciales, Vol. 31 No. 134, pp. 20-29.

Ashby, W.R. (1991), "Requisite variety and its implications for the control of complex systems", In Facets of Systems Science, Springer, Boston, MA, pp. 405-417.

Barile, S., Pellicano, M., Polese, F. (eds.) (2018), Social Dynamics in a Systems Perspective, Springer, Cham.

Barile, S. and Saviano, M. (2018), "Complexity and sustainability in management: insights from a systems perspective", in Social Dynamics in a Systems Perspective, Springer, Cham, pp. 39-63.

Barile, S., Saviano, M. and Caputo, F. (2014), “A systems view of customer satisfaction”, In National Conference "Excellence in Quality, Statistical Quality Control and Customer Satisfaction", University Campus “Luigi Einaudi”, University di Torino, 18-19 September.

Barnard, C. (1938), The Functions of the Executive, Harvard University Press, Cambridge.

Bashir, M. and Farooq, R. (2019), "The synergetic effect of knowledge management and business model innovation on firm competence", International Journal of Innovation Science, Vol. 11 No. 3, pp. 362-387.

Baumgartner, R.J. and Ebner, D. (2010), "Corporate sustainability strategies: sustainability profiles and maturity levels", Sustainable Development, Vol. 18 No. 2, pp. 76-89.

Beer, S. (1989), Viable System Model. Viable Systems Model, Wiley, Chicester.

Bertoncelj, A. and Kovač, D. (2009), "Success factors and competencies in organisational evolution", Kybernetes, Vol. 38 No. 9, pp. 1508-1517.

Bowen, F. (2014), After Greenwashing: Symbolic Corporate Environmentalism and Society, Cambridge University Press.

Breidbach, C.F. and Brodie, R.J. (2017), "Engagement platforms in the sharing economy: conceptual foundations and research directions", Journal of Service Theory and Practice, Vol. 27 No. 4, pp. 761-777.

Burhan, A.H.N. and Rahmanti, W. (2012), "The impact of sustainability reporting on company performance", Journal of Economics, Business, and Accountancy Ventura, Vol. 15 No. 2, pp. 257-272. 
$\mathrm{K}$

50,3

652

Calabrese, A. and Lancioni, F. (2008), "Analysis of corporate social responsibility in the service sector: does exist a strategic path?”, Knowledge and Process Management, Vol. 15 No. 2, pp. 107-125.

Čančer, V. and Mulej, M. (2010), "The dialectical systems theory's capacity for multi-criteria decisionmaking", Systems Research and Behavioral Science, Vol. 27 No. 3, pp. 285-300.

Caputo, F. (2017), "Reflecting upon knowledge management studies: insights from systems thinking", Int. J. Knowledge Management Studies, Vol. 8 Nos 3/4, pp. 177-198.

Caputo, F. and Evangelista, F., In Information Resources Management Association (USA) (2019), "Information sharing and cognitive involvement for sustainable workplaces", (Ed.), Corporate Social Responsibility: Concepts, Methodologies, Tools, and Applications, IGI Global, pp. 1403-1420.

Caputo, F., Buhnova, B. and Walletzký, L. (2018), "Investigating the role of smartness for sustainability: insights from the smart grid domain”, Sustainability Science, Vol. 13 No. 5, pp. 1299-1309.

Caputo, F., Walletzky, L. and Štepánek, P. (2019), "Towards a systems thinking based view for the governance of a smart city's ecosystem”, Kybernetes, Vol. 48 No. 1, pp. 108-123.

Carrero, I. and Valor, C. (2012), "CSR-labelled products in retailers' assortment”, International Journal of Retail and Distribution Management, Vol. 40 No. 8, pp. 629-652.

Carroll, A.B. (1999), "Corporate social responsibility: Evolution of a definitional construct", Business and Society, Vol. 38 No. 3, pp. 268-295.

Chaudhary, R. (2017), "Corporate social responsibility and employee engagement: can CSR help in redressing the engagement gap?", Social Responsibility Journal, Vol. 13 No. 2, pp. 323-338.

Checkland, P. (1994), "Systems theory and management thinking", American Behavioral Scientist, Vol. 38 No. 1, pp. 75-91.

Davis, K. (1960), “Can business afford to ignore social responsibilities?”, California Management Review, Vol. 2 No. 3, pp. 70-76.

Deigh, L., Farquhar, J., Palazzo, M. and Siano, A. (2016), “Corporate social responsibility: Engaging the community”, Qualitative Market Research: An International Journal, Vol. 19 No. 2, pp. 225-240.

Del Giudice, M., Khan, Z., De Silva, M., Scuotto, V., Caputo, F. and Carayannis, E. (2017), "The microlevel actions undertaken by owner-managers in improving the sustainability practices of cultural and creative small and medium enterprises: a United Kingdom-Italy comparison", Journal of Organizational Behavior, Vol. 38 No. 9, pp. 1396-1414.

Docherty, P., Kira, M. and Shani, A.R. (Eds). (2008), Creating Sustainable Work Systems: Developing Social Sustainability, Routledge, London.

Espejo, R. (1990), “The viable system model”, Systems Practice, Vol. 3 No. 3, pp. 219-221.

Espejo, R. and Espinosa, A. (2015), "Governance for sustainability: learning from VSM practice", Kybernetes, Vol. 44 Nos 6/7, pp. 955-969.

Espinosa, A. and Walker, J. (2017), Complexity Approach to Sustainability, A: Theory and Application, (Vol. 5). World Scientific, Singapore.

Espinosa, A., Harnden, R. and Walker, J. (2007), "Beyond hierarchy: a complexity management perspective", Kybernetes, Vol. 36 Nos 3/4, pp. 333-347.

Espinosa, A., Harnden, R. and Walker, J. (2008), “A complexity approach to sustainability-Stafford beer revisited”, European Journal of Operational Research, Vol. 187 No. 2, pp. 636-651.

Foss, N.J. and Saebi, T. (2018), "Business models and business model innovation: between wicked and paradigmatic problems”, Long Range Planning, Vol. 51 No. 1, pp. 9-21.

Harrison-Hill, T. (2001), "How far is a long way? Contrasting two cultures' perspectives of travel distance", Asia Pacific Journal of Marketing and Logistics, Vol. 13 No. 3, pp. 3-17.

Holbrook, M.B. (Ed.). (1999), Consumer Value: A Framework for Analysis and Research, Psychology Press. 
Holland, J.H. (1992), Adaptation in Natural and Artificial Systems: An Introductory Analysis with Applications to Biology, Control, and Artificial Intelligence, MIT press.

Hollensen, S. (2010), Marketing Management: A Relationship Approach, Pearson Education.

Jahdi, K.S. and Acikdilli, G. (2009), "Marketing communications and corporate social responsibility (CSR): marriage of convenience or shotgun wedding?", Journal of Business Ethics, Vol. 88 No. 1, pp. 103-113.

Jensen, H.J. (2018), “Complexity science research philosophy”, In Mitleton-Kelly E., Paraskevas A. and Day C. (Eds.), Handbook of Research Methods in Complexity Science: Theory and Applications, Edward Elgar Publishing, London, pp. 2-3.

Knez-Riedl, J., Mulej, M. and Dyck, R.G. (2006), "Corporate social responsibility from the viewpoint of systems thinking”, Kybernetes, Vol. 35 Nos 3/4, pp. 441-460.

Knowles, K. and Espinosa, A. (2009), "Towards an holistic framework for environmental change: the role of normative behaviour and informal networking to enhance sustainable business practices", Systemic Practice and Action Research, Vol. 22 No. 4, pp. 275-291.

Krishnaswami, S. and Subramaniam, V. (1999), "Information asymmetry, valuation, and the corporate spin-off decision", Journal of Financial Economics, Vol. 53 No. 1, pp. 73-112.

Laszlo, C. (2003), The Sustainable Company: How to Create Lasting Value through Social and Environmental Performance, Island Press, London.

Lepskiy, V. (1998), "The concept of subject-oriented computerization of control activity", Moscow, Institute of Psychology, RAS.

Lepskiy, V. (2018), "Decision support ontologies in Self-Developing Reflexive-Active environments", IFAC-Papers OnLine, Vol. 51 No. 30, pp. 504-509.

Luciano, E.V., Gil-Lafuente, A.M., González, A.G. and Boria-Reverter, S. (2013), "Forgotten effects of corporate social and environmental responsibility", Kybernetes, Vol. 42 No. 5, pp. 736-753.

McWilliams, A. and Siegel, D. (2001), "Corporate social responsibility: a theory of the firm perspective", Academy of Management Review, Vol. 26 No. 1, pp. 117-127.

Marin, D. and Verdier, T. (2008), "Power inside the firm and the market: a general equilibrium approach", Journal of the European Economic Association, Vol. 6 No. 4, pp. 752-788.

Menichini, T. and Rosati, F. (2014), "The strategic impact of CSR consumer-company alignment", Procedia - Social and Behavioral Sciences, Vol. 109, pp. 360-364.

Mosca, F. and Civera, C. (2017), "The evolution of CSR: an integrated approach”, Symphonya. Emerging Issues in Management, No. 1, pp. 16-35.

Mulej, M. (1976), "Toward the dialectical systems theory", In Trappl, R., Hanika, P. and Pichler, F. (Eds), Progress in Cybernetics and Systems Research. Austrian Society for Cybernetic Studies, Vienna.

Mulej, M., Rebernik, M. and Bradač, B. (2006), "Cooperation and opportunistic behaviour in transformational outsourcing”, Kybernetes, Vol. 35 Nos 7/8, pp. 1005-1013.

Nooteboom, B., Van Haverbeke, W., Duysters, G., Gilsing, V. and Van den Oord, A. (2007), "Optimal cognitive distance and absorptive capacity", Research Policy, Vol. 36 No. 7, pp. 1016-1034.

Panagiotakopoulos, P.D., Espinosa, A. and Walker, J. (2016), "Sustainability management: insights from the viable system model”, Journal of Cleaner Production, Vol. 113, pp. 792-806.

Papadas, K.K., Avlonitis, G.J. and Carrigan, M. (2017), "Green marketing orientation: Conceptualization, scale development and validation”, Journal of Business Research, Vol. 80, pp. 236-246.

Perko, I. and Mlinaric, F. (2016), "Decreasing information asymmetry by sharing business data: a case of business non-payers sharing agency", International Journal of Risk Assessment and Management, Vol. 19 Nos 1/2, pp. 54-67.

Perko, I. and Ototsky, P. (2016), "Business ecosystems requirements for big data”, International Journal of Transitions and Innovation Systems, Vol. 5 Nos 3/4, pp. 329-352. 
$\mathrm{K}$

50,3

Pirsch, J., Gupta, S. and Grau, S.L. (2007), "A framework for understanding corporate social responsibility programs as a continuum: an exploratory study", Journal of Business Ethics, Vol. 70 No. 2, pp. 125-140.

Podnar, K. and Golob, U. (2007), “CSR expectations: the focus of corporate marketing”, Corporate Communications: An International Journal, Vol. 12 No. 4, pp. 326-340.

Porter, M.E. and Kramer, M.R. (2006), "The link between competitive advantage and corporate social responsibility”, Harvard Business Review, Vol. 84 No. 12, pp. 78-92.

Richter, U.H. and Arndt, F.F. (2018), "Cognitive processes in the CSR decision-making process: a sensemaking perspective”, Journal of Business Ethics, Vol. 148 No. 3, pp. 587-602.

Ritter, T. and Geersbro, J. (2018), "Multidexterity in customer relationship management: Managerial implications and a research agenda", Industrial Marketing Management, Vol. 69, pp. 74-79.

Saviano, M., Barile, S. and Caputo, F. (2017), "Re-affirming the need for systems thinking in social sciences: a viable systems view of smart city", In Vrontis S., Weber T., Tsoukatos E. (Eds), Global and National Business Theories and Practice: bridging the past with the Future, EuroMed Pres, Cyprus, pp. 1552-1567.

Saviano, M., Caputo, F., Mueller, J. and Belyaeva, Z. (2018), "Competing through consonance: a stakeholder engagement view of corporate relational environment”, Sinergie, Vol. 105, pp. 61-80.

Schwaninger, M. (2006), "Theories of viability: a comparison", Systems Research and Behavioral Science, Vol. 23 No. 3, pp. 337-347.

Singh, P. and Giacosa, E. (2019), "Cognitive biases of consumers as barriers in transition towards circular economy”, Management Decision, Vol. 57 No. 4, pp. 921-936.

Soltani, Z. and Navimipour, N.J. (2016), "Customer relationship management mechanisms: a systematic review of the state of the art literature and recommendations for future research", Computers in Human Behavior, Vol. 61, pp. 667-688.

Tansley, A.G. (1939), "British ecology during the past quarter-century: the plant community and the ecosystem", The Journal of Ecology, Vol. 27 No. 2, pp. 513-530.

Tomer, J. (2002), The Human Firm: A Socio-Economic Analysis of Its Behaviour and Potential in a New Economic Age, Routledge.

Tronvoll, B., Barile, S. and Caputo, F. (2018), "A systems approach to understanding the philosophical foundation of marketing studies”, In Barile, S., Pellicano, M., Polese, F. (Eds.), Social Dynamics in a Systems Perspective, (pp. 1-18). Springer, Cham.

Uhl-Bien, M., Marion, R. and McKelvey, B. (2007), “Complexity leadership theory: Shifting leadership from the industrial age to the knowledge era", The Leadership Quarterly, Vol. 18 No. 4, pp. 298-318.

World Business Council for Sustainable Development (WBCSD) (1999), Corporate Social Responsibility, WBCSD, Geneva.

Wu, D.D., Belak, J. and Rozman, M.P. (2012), "Business ethics from Aristotle, Kant and Mill's perspective", Kybernetes, Vol. 41 No. 10, pp. 1607-1624.

Zenko, Z., Rosi, B., Mulej, M., Mlakar, T. and Mulej, N. (2012), "Mulej's dialectical systems theory—a proven next step after Bertalanffy's general systems theory", In 2012 IEEE International Conference on Complex Systems (ICCS), IEEE, pp. 1-8.

\section{Further reading}

Bowen, H.R. (1953), Social Responsibilities of the Businessman, University of IA Press. IA.

Norton, B.G. (2005), Sustainability: A philosophy of adaptive ecosystem management, University of Chicago Press.

Zack, M.H. (2003), "Rethinking the knowledge-based organization”, MIT Sloan Management Review, Vol. 44 No. 4, pp. 67-72. 


\section{About the author}

Francesco Caputo $(\mathrm{PhD})$ is a Senior Researcher (Rtd B) at the Department of Economics, Management, and Institutions (DEMI), University of Naples "Federico II". He is a Member of Scientific Board of Reald Summer School (University of Reald Vlore - Albania) and President of the Association for Research on Viable Systems. He is the author of more than 100 publications, he is a member of the editorial boards of several international journals, and he serves as a reviewer for several Italian and international journals. He was a finalist at the 2012/2013 Emerald/EMRBI Business Research Award and he has won the Best Presentation Award at the 2016 B.S.Lab Symposium, the Best Paper Award at the 19th Toulon-Verona (ICQSS) Conference, the 2017 Outstanding Reviewer for Kybernetes journal and the Best Commended Paper at the 2017 WOSC Congress. His main research interests include but they are not limited to complexity, knowledge management, and systems thinking. Francesco Caputo can be contacted at: francesco.caputo2@ unina.it
Antecedent role of information asymmetry

For instructions on how to order reprints of this article, please visit our website: www.emeraldgrouppublishing.com/licensing/reprints.htm Or contact us for further details: permissions@emeraldinsight.com 